\title{
O USO DO BRINQUEDO TERAPÊUTICOEA HUMANIZAÇÃO DA ASSISTÊNCIA À CRIANÇA CIRÚRGICA
}

DOI: 10.5327/Z1414-4425201900030001

A necessidade de se submeter a uma cirurgia é percebida por muitas pessoas como algo preocupante e capaz de gerar alto nível de estresse. Em minha trajetória profissional, a experiência em cuidar de adultos e crianças nos períodos pré e pós-operatório mostrou que a desinformação parece ser o grande problema.

Profissionais de saúde nem sempre estão sensibilizados para a importância de acolher os pacientes nesse momento em que se encontram tão vulneráveis. O medo do desconhecido desorganiza o indivíduo, que se sente inseguro. Informar claramente sobre o procedimento cirúrgico, utilizando linguagem adequada e mostrar-se receptivo aos seus receios e angústias, torna-se fundamental no momento.

Se para os adultos não é nada fácil realizar uma cirurgia, para as crianças pode se tornar um evento traumático, com repercussões significativas no seu desenvolvimento emocional. Elas também precisam ser informadas sobre o que vai acontecer antes, durante e após a cirurgia, entretanto frequentemente esse direito lhe é negado.

Por acreditarem que a criança não tem capacidade para compreender a situação e com receio de que ela venha a sofrer ainda mais ao conversar sobre o procedimento, os adultos optam, muitas vezes, por não dizer a verdade, omitindo fatos ou contando histórias fantasiosas, muito distantes da realidade $^{1}$. E, ao acordar da anestesia, ela se sente confusa e com raiva, por ter sido traída pelas pessoas em quem confiava. Não coopera com os procedimentos, como era de se esperar, aumentando o risco de extubações acidentais, bem como de retirada inadvertida de cateteres e sondas.

A capacidade de compreensão da criança costuma ser subestimada pelo adulto; contudo, quando são utilizadas estratégias de comunicação apropriadas ao seu estágio de desenvolvimento, ela pode nos surpreender.

Uma dessas estratégias é o brinquedo, tão importante para a criança como o trabalho para o adulto. Tem inúmeras funções, entre as quais destaco sua capacidade de favorecer o estabelecimento de um vínculo de confiança com o profissional que cuida dela. A sua inserção em instituições de saúde é indispensável e possibilita a realização do cuidado atraumático, que consiste em oferecer um cuidado livre de traumas emocionais, reconhecido como uma das formas de humanização do cuidado em pediatria ${ }^{1}$.

O brinquedo terapêutico (BT) é uma modalidade lúdica muito utilizada no contexto hospitalar, seja como forma de possibilitar à criança aliviar a tensão, ao dramatizar uma situação atípica para ela (dramático), transformar uma atividade terapêutica em atividade lúdica (capacitador de funções) ou, ainda, como ferramenta poderosa que auxilia o adulto a explicar, de forma simples e clara, o que acontecerá com ela (instrucional).

Um estudo realizado com 30 crianças entre 3 e 5 anos, submetidas à cirurgia de pequeno porte e preparadas previamente com o BT, aponta que a maioria delas entrou espontaneamente na sala operatória $(73,3 \%)$ e sem resistir à separação da mãe (80,0\%), colaborando para o procedimento anestésico $(53,3 \%)$ e despertando da anestesia tranquilamente $(87 \%)^{2}$.

Bonecos representando a equipe cirúrgica, a criança e seus pais, bem como materiais hospitalares, como gorros, máscara, avental, seringas e equipo de soro, entre outros, foram utilizados neste estudo para dramatizar a realização da cirurgia. O número reduzido de comportamentos que evidenciam medo e estresse entre as crianças, como chorar, agitar-se, debater-se ou gritar, reforça os efeitos benéficos do BT no preparo da criança para a cirurgia ${ }^{2}$.

Embora existam várias publicações sobre os efeitos do BT na redução da ansiedade e do estresse em crianças submetidas a procedimentos hospitalares, a maioria delas não oferece evidências consistentes que comprovem esse fato, como mostra uma revisão sistemática publicada mais recentemente ${ }^{3}$.

Todavia, um estudo clínico randomizado traz resultados mais robustos sobre a eficácia do BT em diminuir a ansiedade infantil diante de procedimentos invasivos, dolorosos e/ ou estressantes. Foi realizado com 208 crianças, entre 3 e 12 anos, submetidas à retirada de gesso ortopédico, sendo que 103 foram selecionadas aleatoriamente para receber preparo prévio com $\mathrm{BT}$ e as demais constituíram o grupo controle. No geral, as crianças preparadas com o BT apresentaram menos manifestações emocionais negativas durante o 
procedimento; entretanto, a redução dos níveis de ansiedade foi mais evidente nas crianças de três e sete anos que brincaram antes do procedimento ${ }^{4}$.

Embora a literatura seja vasta em relação ao uso do BT nos diferentes níveis de atenção à saúde, especialmente por profissionais de enfermagem, ressalta-se, contudo, que seu emprego ainda é modesto na prática clínica.

Nesse sentido, a Legislação do Exercício Profissional em Enfermagem reconhece, como competência de toda a equipe de enfermagem que atua na área pediátrica, o emprego do brinquedo/BT na assistência da criança hospitalizada e de sua família. Cabe, portanto, ao enfermeiro prescrever e supervisionar essa atividade, quando realizada pelo auxiliar ou pelo técnico de enfermagem ${ }^{5}$.
Diante de todos os esforços para que o BT seja amplamente utilizado pelos profissionais de saúde no atendimento à criança, espero que, em um futuro muito próximo, o seu uso seja um procedimento tão rotineiro quanto a higienização das mãos ou a prevenção de quedas. Brincar também é cuidar!

\section{Fabiane de Amorim Almeida $(\bullet$}

Enfermeira, doutora em Psicologia Escolar e do Desenvolvimento Humano pela Universidade de São Paulo (USP). Professora

da Faculdade Israelita de Ciências da Saúde Albert Einstein (FICSAE) e líder do Grupo de Estudos do Brinquedo (GEBRINq), vinculado ao Conselho Nacional de Desenvolvimento Cientifico e Tecnológico (CNPq).

\section{REFERÊNCIAS}

1. Hockenberry MJ, Wilson D, Winkelstein ML, editores. Wong: Fundamentos de Enfermagem Pediátrica. 10a ed. São Paulo: Elsevier; 2018.

2. Paladino $\mathrm{CM}$, Carvalho R, Almeida FA. Brinquedo terapêutico no preparo para a cirurgia: comportamentos de pré-escolares no período transoperatório. Rev Esc Enferm USP. 2014;48(3):423-9. http://doi. org/10.1590/S0080-623420140000300006

3. Silva RD, Austregésilo SC, Ithamar L, Lima LS. Therapeutic play to prepare children for invasive procedures: a systematic review. J Pediatr. 2017;93(1):6-16. http://doi.org/10.1016/j.jped.2016.06.005
4. Wong CL, Ip WY, Kwok BMC, Choi KC, Ng BKW, Chan CWH. Effects oftherapeutic play on childrenundergoing cast-removalprocedures: a randomized controlled trial. BMJ Open. 2018;8:e21071. http:// doi.org/10.1136/bmjopen-2017-021071

5. Conselho Federal de Enfermagem. Resolução COFEN n 546/2017, de 9 de maio de 2017. Atualiza norma para utilização da técnica do brinquedo/brinquedo terapêutico pela equipe de enfermagem na assistência à criança hospitalizada [Internet]. Brasília: COFEN; 2017 [acessado em 31 jul. 2019]. Disponível em: http://www.cofen.gov. br/resolucao-cofen-no-05462017_52036.html 